\title{
A Nucleotide Substitution in the Promoter of Human Angiotensinogen Is Associated with Essential Hypertension and Affects Basal Transcription In Vitro
}

\author{
Ituro Inoue, ${ }^{*}$ Toshiaki Nakajima, ${ }^{*}$ Christopher S. Williams, ${ }^{*}$ John Quackenbush, ${ }^{*}$ Robert Puryear, ${ }^{*}$ Michael Powers, ${ }^{*}$ \\ Tong Cheng, ${ }^{*}$ Erwin H. Ludwig, ${ }^{*}$ Arya M. Sharma, ${ }^{\star}$ Akira Hata, ${ }^{\S}$ Xavier Jeunemaitre, \\ *Howard Hughes Medical Institute and Department of Human Genetics, University of Utah Health Sciences Center, Salt Lake City, Utah \\ 84112; Department of General Internal Medicine and Nephrology, Freie Universitat, D-12200 Berlin, Germany; ${ }^{\S}$ Department of Public \\ Health, Hokkaido University School of Medicine, Sapporo 070, Japan; and "INSERM U36 and Laboratoire de Biologie Moléculaire, \\ Hôpital Broussais, 75005 Paris, France
}

\begin{abstract}
In earlier studies, we provided statistical evidence that individual differences in the angiotensinogen gene, the precursor of the vasoactive hormone angiotensin II, constitute inherited predispositions to essential hypertension in humans (1). We have now identified a common variant in the proximal promoter, the presence of an adenine, instead of a guanine, $6 \mathrm{bp}$ upstream from the initiation site of transcription, in significant association with the disorder. Tests of promoter activity and DNA binding studies with nuclear proteins suggest that this nucleotide substitution affects the basal transcription rate of the gene. These observations provide some biological insight about the possible mechanism of a genetic predisposition to essential hypertension; they may also have important evolutionary implications. (J. Clin. Invest. 1997. 99:1786-1797.) Key words: essential hypertension $\cdot$ angiotensinogen - molecular variant $\cdot$ promoter $•$ transcription
\end{abstract}

\section{Introduction}

While the molecular basis of rare inherited human diseases is being unraveled at a rapid pace, the identification of genetic determinants of common human disorders such as diabetes, hypertension, coronary heart disease, and obesity remains problematic. Lack of phenotypic specificity, multiple causation, genetic heterogeneity, and the mild, insidious onset and progression of these metabolic disorders are variously identified as sources of this difficulty, and indeed, these very attributes are often used in the definition of a common disease (2). Perhaps the most fundamental, defining feature of such disorders, however, is that molecular variation predisposes individuals through mild, graded functional differences rather than through discrete biological alterations leading to gain or loss of function.

Address correspondence to Jean-Marc Lalouel, M.D., D.Sc., Howard Hughes Medical Institute, Eccles Institute of Human Genetics, 6th Floor, University of Utah Health Sciences Center, Salt Lake City, UT 84112. Phone: 801-581-4311; FAX: 801-585-3910; E-mail: jml@ howard.genetics.utah.edu

Received for publication 15 November 1996 and accepted in revised form 14 January 1997.

J. Clin. Invest.

(C) The American Society for Clinical Investigation, Inc.

0021-9738/97/04/1786/12 \$2.00

Volume 99, Number 7, April 1997, 1786-1797
Essential hypertension offers a typical paradigm of common disease. This leading cause of human cardiovascular morbidity and mortality, which afflicts $>50 \%$ of the population of the United States by age 65 (3), is characterized by a progressive but asymptomatic rise in blood pressure over a lifetime. It is usually detected in the course of a systematic physical examination; from a medical standpoint, the goal is to detect and control high blood pressure before severity or advanced organ damage lead to clinical endpoints such as stroke, heart failure, or kidney failure. Little is known of the genetic basis underlying individual susceptibility to the disease (4). By contrast, rare mendelian syndromes involving hypertension are characterized by early manifestation, by distinctive clinical signs or biochemical alterations, and by recognized molecular defects leading to ectopic gene expression (5), constitutive gene activation (6), or marked enzymatic deficiency (7).

In a previous report (1), we provided genetic evidence that molecular variants of the angiotensinogen gene (AGT), ${ }^{1}$ the precursor of the vasoactive hormone angiotensin-II, constitute inherited predispositions to essential hypertension in Caucasians. The supporting data were of a statistical nature, resting on three observations: $(a)$ genetic linkage between AGT and hypertension in affected siblings; $(b)$ association of hypertension with a molecular variant of the gene encoding the presence of a threonine instead of a methionine at residue 235 of mature angiotensinogen (T235 versus M235); and (c) association between this molecular variant and plasma angiotensinogen concentrations, with levels $15-40 \%$ higher in T235 homozygotes than in M235 homozygotes. Further observations have extended these initial findings. The association between AGT genotype at residue 235 and plasma angiotensinogen was confirmed in both male and female caucasian children (8). The association with essential hypertension was also significant in Japanese subjects (9). Furthermore, T235 occurred at higher frequency in preeclampsia, a hypertensive disorder of pregnancy, than in women with normal pregnancy outcomes (10); additional support was provided by an independent linkage study (11). As reviewed elsewhere (Jeunemaitre, X., I. Inoue, C. Williams, A. Charru, J. Tichet, M. Powers, A.M. Sharma, A.P. Giminez-Roqueplo, A. Hata, P. Corvol, et al., manuscript submitted), while other studies confirm this association, a characteristic feature of the occasional studies in which statistical significance was not achieved is the low statistical power afforded by their small sample size.

Variant T235 of AGT may be directly causal, or it may act

1. Abbreviations used in this paper: AGT, angiotensinogen gene; CAT, chloramphenicol acetyl transferase. 
as a marker for an as yet unidentified molecular variant. Residue 235 occurs in a region of the protein which displays little conservation in distant mammals such as humans and mice. Furthermore, it appears distant from the site cleaved by renin, when one considers the structure of the homologous protein $\alpha_{1}$-antitrypsin (12).

We now report that a molecular variant in the proximal promoter of the AGT gene, an adenine instead of a guanine six nucleotides upstream from the site of transcription initiation, $\mathrm{A}(-6)$, is in very tight linkage disequilibrium with T235 and marks the original form of the gene. Tests of promoter function in cultured cells and studies of binding between AGT oligonucleotides and nuclear proteins strongly suggest that the substitution at nucleotide -6 affects specific interactions between at least one trans-acting nuclear factor and the promoter of AGT, thereby influencing the basal rate of transcription of the gene. These observations suggest a biological mechanism by which individual differences in the AGT gene may predispose carriers to the development of essential hypertension. They also suggest an evolutionary scenario to account for the emergence of common human disorders, which may fit the "thrifty genotype" hypothesis advanced by James Neel more than 30 years ago (13).

\section{Methods}

Genotyping molecular variants of human angiotensinogen. The polymorphism at nucleotide -6 was determined by mutagenically separated PCR (14). Three primers were included in the reaction: a common forward primer, 5'-GTGTCGCTTCTGGCATCTGTCCTTCTGG-3', a short reverse primer, 5' - TACCCAGAACAACGGCAGCTTCTTCCACT-3', for the detection of allele $\mathrm{A}(-6)$ and a long reverse primer, 5' -CCGGTTACCTTCTGCTGTAGAGCCCAGAACAACGGCAGCTTCTTCCATC-3', for the detection of allele $\mathrm{G}(-6)$. The polymorphism at amino acid residue 235 was characterized by allele specific oligonucleotide hybridization as described (1).

$D N A$ sequencing of selected segments of $A G T$ in primates. DNA segments encompassing nucleotide -6 and codon 235 were enzymatically amplified with primers derived from the sequence of human AGT, and DNA sequencing was performed using a Taq DyeDeoxy Terminator protocol on an ABI 373A sequenator (Applied Biosystems, Inc., Foster City, CA).

Expression of human AGT in COS-1 cells. The entire coding sequence of human AGT was placed under the control of the major late promoter of adenovirus in the expression vector pMT2 (Genetics Institute, Cambridge, MA). Two constructs were generated, encoding either a threonine or a methionine at residue 235. COS- 1 cells were transfected by electroporation with a Gene-pulser (Bio-Rad Laboratories, Hercules, CA) as described (15). In pulse-chase experiments, the transfected cells were first incubated for $48 \mathrm{~h}$ in complete medium. Thereafter, medium was changed to methionine and cysteine free DMEM without serum. After 10 min preincubation, the cells were pulse-labeled with $100 \mu \mathrm{Ci} / \mathrm{ml}$ Trans ${ }^{35} \mathrm{~S}$-label (ICN, Costa Mesa, CA), for $10 \mathrm{~min}$ at $37^{\circ} \mathrm{C}$. The cells were washed twice with complete DME supplemented with methionine $(20 \mu \mathrm{g} / \mathrm{ml})$ and cysteine $(20 \mu \mathrm{g} / \mathrm{ml})$, and the chase was pursued for $8 \mathrm{~h}$. At the time points indicated, cells and conditioned media were collected. The cells were lysed by two cycles of freezing and thawing in a buffer consisting of $25 \mathrm{mM}$ Tris- $\mathrm{HCl}, 50 \mathrm{mM} \mathrm{NaCl}, 2 \% \mathrm{NP}-40,0.2 \%$ SDS, $0.5 \%$ sodium deoxycholate, and $1 \mathrm{mM}$ PMSF, $\mathrm{pH}$ 7.4. The cell suspension was cleared by centrifugation at $18,000 \mathrm{rpm}$ for $20 \mathrm{~min}$. Immunoprecipitation was performed by a standard protocol (16) with antihuman angiotensinogen polyclonal antibody, kindly provided by Duane Tewksbury (Marshfield Foundation, Marshfield, WI). The samples were separated on a $10 \%$ SDS-PAGE gel. The gels were ana- lyzed on a PhosphorImager (Molecular Dynamics, Sunnyvale, CA) and exposed to Kodak x-ray film.

For kinetic studies, angiotensinogen was concentrated from conditioned media of transfected COS-1 cells and incubated with purified human renin $(250 \mathrm{pM}$, a gift from Dr. Matthews, HoffmannLaRoche, Nutley, NJ) as previously described (15).

Expression vectors for promoter studies. A human AGT genomic clone isolated from a gridded P1 library (17), with guanine at nucleotide -6 , together with genomic DNA derived from an individual homozygous for $A(-6)$, served as templates to amplify enzymatically promoter segments spanning -256 to +90 (vector I), -70 to +90 (vector II) and -256 to -17 (vector III) of the AGT gene, respectively, and additional restriction enzyme sites were created during the amplification. The reaction products were digested with KpnI and HindIII followed by subcloning into the luciferase reporter system based on the pGL2 basic vector (Promega Corp., Madison, WI). Sitedirected mutagenesis in the -6 region of the AGT promoter was carried out by the primer-overlap method (18). All inserts and junction segments were verified in their entirety by DNA sequencing.

Cell culture. The human hepatoma cell line HepG2, the human embryonal kidney cell line, 293, and COS-1 cells were obtained from the American Type Tissue Collection and maintained in DME supplemented with $10 \%$ FCS (Hyclone, Logan, UT) and cultured at $37^{\circ} \mathrm{C}$ under an atmosphere containing $5 \% \mathrm{CO}_{2}, 95 \%$ air.

Transfection and reporter assay. Plasmids were grown in DH5 $\alpha$ or in the dam, dcm deficient strain, DM1 (Gibco BRL, Gaithersburg, MD), followed by purification on QIAGEN columns (QIAGEN, Inc., Chatsworth, CA). DNA concentrations were determined by spectrophotometry at least twice and further confirmed by agarose gel analysis. Cells were transfected with the reporter construct $(2.5$ $\mu \mathrm{g})$ together with a control vector for CAT expression, pCAT control $(1.25 \mu \mathrm{g})$ provided by Promega Corp., by a calcium phosphate transfection protocol using modified bovine serum (Stratagene, Inc., La Jolla, CA). Briefly, the cells were plated onto $35 \mathrm{~mm}$ 6-well plastic dishes, $5 \times 10^{5}$ per dish, and incubated for $24 \mathrm{~h}$ before transfection. At the time of transfection, the medium was changed to $6 \%$ modified bovine serum in DME. Each experiment involved triplicate or quadruplicate dishes for each construct. $2 \mathrm{~d}$ after transfection, the cells were harvested with a lysis buffer (Promega Corp.), and luciferase activity was measured using a luciferase assay system (Promega Corp.) in a Luminometer (Turner design, Promega Corp.); CAT expression of the same extract was measured by an ELISA (Boehringer Mannheim Biochemicals, Indianapolis, IN).

Gel mobility shift assay. Nuclear extracts from HepG2 or other mammalian cell lines were prepared as described (19). Final protein concentrations of the extracts were adjusted to $2-4 \mathrm{mg} / \mathrm{ml}$. Aliquots were stored at $-80^{\circ} \mathrm{C}$ in Dignam's buffer D $(20 \mathrm{mM}$ Hepes, $\mathrm{pH} 7.9$, $20 \%$ (vol/vol) glycerol, $0.1 \mathrm{M} \mathrm{KCl}, 0.2 \mathrm{mM}$ EDTA, $0.1 \mathrm{mM}$ (4[2-aminoethyl]benzenesulfonyl fluoride) AEBSF, 0.5 mM DTT). Double stranded oligonucleotides spanning the -6 nucleotide region of human AGT were labeled with $\left[\gamma^{-32} \mathrm{P}\right]$ ATP by a kination reaction and used as probes in gel mobility shift assay as described (20). In a typical experiment, the binding reaction $(20 \mu \mathrm{l})$ contained $10 \mathrm{mM}$ Hepes, pH 7.9, $5 \mathrm{mM} \mathrm{MgCl}_{2}, 1 \mathrm{mM}$ EDTA, $0.5 \mathrm{mM}$ DTT, $100 \mathrm{mM} \mathrm{KCl}, 10 \%$ Glycerol, and $2 \mu \mathrm{g}$ of poly(dI-dC). Nuclear extract $(5 \mu \mathrm{g})$ was preincubated with poly (dI-dC) on ice for $20 \mathrm{~min}$, followed by incubation with radiolabeled probe at $25^{\circ} \mathrm{C}$ for $15 \mathrm{~min}$. The binding reaction was resolved on a $4 \%$ native polyacrylamide gel in $0.5 \times \mathrm{TBE}$ buffer. The gel was run at $200 \mathrm{~V}$ for $2 \mathrm{~h}$ or longer, dried, and exposed on Kodak $\mathrm{XAR}$ film at $-80^{\circ} \mathrm{C}$. Competition experiments were performed by adding from 12.5- to 100-fold molar excess of unlabeled doublestranded oligonucleotides to the preincubation mixture. G23 and A23 correspond to segments of AGT comprised of 23 nucleotides, centered on site -6 , with $\mathrm{G}$ or $\mathrm{A}$ at this position, respectively. Control 1 and control 2 are double-stranded oligonucleotides of random composition with sequences 5'-TCGACGGCCAAGCCGGAAGTGAGTGCC-3' and 5'-CTAGTACTACATGATGATTGAAGTACTTGA-3', respectively. Sp1 and Oct-1 oligonucleotides, with consensus 
binding sites for the corresponding transcription factors, were obtained from Promega Corp.

Purification of binding proteins and microsequencing. Human T-cell leukemia cells, MOLT4, were grown in RPMI 1640 supplemented with $10 \%$ FCS. Nuclear extract from the cell was prepared as described (21). The extract was applied onto QAE sepharose (Pharmacia LKB Biotechnology Inc., Piscataway, NJ) in buffer A $(50 \mathrm{mM}$ Tris- $\mathrm{HCl}, \mathrm{pH}$ 7.9, $1 \mathrm{mM}$ EDTA, $10 \%$ glycerol, $1 \mathrm{mM}$ DTT, $2.5 \mu \mathrm{M}$ E-64, $0.2 \mathrm{mM}$ AEBSF). After washing, proteins were eluted with buffer A containing $\mathrm{NaCl}$ by a step-wise method. The eluted fractions were monitored for their binding activity, and fractions exhibiting either the specific or the nonspecific binding complex were diluted with buffer A, and loaded onto an AGT G23 DNA affinity column.

The DNA affinity column was prepared as follows. G23 oligonucleotides, which contain additional protruding sticky ends, were annealed, phosphorylated with T4 polynucleotide kinase and ligated together with T4 ligase (New England Biolabs, Beverly, MA). The concatenated DNA fragments were covalently coupled to cyanogen bromide-activated Sepharose 4B (Pharmacia LKB Biotechnology Inc.) as suggested by the supplier. The column was washed with $0.1 \mathrm{M}$ $\mathrm{NaCl}$ in buffer $\mathrm{A}$ and bound proteins were eluted stepwise with increasing concentrations of $\mathrm{NaCl}$ in buffer $\mathrm{A}$.

Purified proteins were separated on a SDS-PAGE followed by transfer to Immobilon membrane (Millipore Corp., Waters Chromatography, Milford, MA). The transferred proteins were stained with $0.1 \%$ Panceau S / $1 \%$ acetic acid, excised and digested with endoproteinase Lys-C (Boehringer Mannheim Biochemicals) as described (22). Briefly, protein $(\sim 10 \mu \mathrm{g})$ was reacted with endoproteinase Lys-C $(2 \mu \mathrm{g})$ in a buffer consisting of $1 \%$ hydrogenated Triton X-100 (Calbiochem Corp., La Jolla, CA), 10\% acetonitrile, $100 \mathrm{mM}$ Tris- $\mathrm{HCl}$, $\mathrm{pH} 8.0$, overnight at $37^{\circ} \mathrm{C}$. Extraction of the peptides from the membrane was facilitated by sonication in the presence of hydrogenated Triton X-100. The samples were separated on a Vydac C-18 reversed phase HPLC column, followed by microsequencing with an ABI model 477A pulsed liquid phase sequencer.

Statistical analysis. The results of promoter expression experiments were first examined by analysis of variance, using the SPSS Statistical Package, version 6.1, as it affords a model that best reflects the actual design of the experiments. For each cell type, the data obtained with vectors I and II were analyzed separately as well as together, with no difference in the conclusions. For simplicity, only the univariate analyses are reported. For either class of vector, the standardized activity, $y_{i j k}$, obtained in experiment $i(i=1, . ., n$, number of experiments) for vector $\mathrm{j}(\mathrm{j}=1,2$; the presence of either $\mathrm{G}$ or $\mathrm{A}$ at nucleotide -6$)$ in replicate $\mathrm{k}(\mathrm{k}=1, . ., 4)$ can be factored into a mean experimental value, $\mu_{\mathrm{i}}$, a mean effect of the substitution at nucleotide $-6, \mu_{\mathrm{j}}$, and a random fluctuation characteristic of the replicate. This model of analysis of variance enables tests of hypothesis for each of the two factors, experiment and substitution, and estimates of mean values for the modalities assumed by each factor. Interaction terms between the effects of experiment and substitution, $\mu_{\mathrm{ij}}$, reflecting the possibility that the effect of the nucleotide substitution may be a function of (including proportional to) the mean value achieved in a given experiment, can also be included and tested. Incorporating such terms provides an indirect measure of the extent to which the data depart from the additivity and linearity conditions implied by the statistical model. All analyses were repeated after logarithmic transformation of the data. Generally, greater significance was achieved after transformation, and in no instance did the transformation affect the conclusions presented here; for the sake of clarity and concision, only analyses of untransformed data are presented. Homogeneity of variances among various combinations of the two factors were tested with Cochran's C test and Bartlett-Box F test.

To guard against unidentified departures from assumption of this analysis of variance model, several additional analyses were performed in all instances. The data were reanalyzed after exclusion of observations which yielded standardized residuals in excess of 2.5 standard deviations. In another approach, the measured activities were standardized to the mean and variance of all eight replicates within each experiment and the means of these standardized activities, for each of vectors with $\mathrm{G}$ or $\mathrm{A}$ at -6 , respectively, calculated over all replicates and experiments were compared by Student's $t$ test. Nonparametric tests were also performed on these activities, including Mann-Witney rank test, Moses test of extreme reactions, and the two-sample test of Kolmogorov-Smirnov. Finally, a one-way analysis of variance was applied to the standardized activities. All data reported in the figures yielded consistent inferences by these various tests, and as a consequence the two-way analyses of variance provide the primary focus of our presentation.

In the mutagenesis study, five vectors were expressed in parallel. As a consequence, the analysis involved a variant effect which could assume either one of five modalities, and this effect contributed four degrees of freedom to the numerator of the F-statistic. This test provides a global assessment of the significance of the -6 position and its immediate neighborhood in transcriptional activity. Tests of significance for individual vectors were performed with Student's $t$ test, contrasting each vector to the wild type, $G(-6)$ vector, and Scheffé's simultaneous confidence intervals were examined in all instances. As an alternative, we also performed single-factor analyses comparing each vector to the construct with $\mathrm{G}$ at position -6 , computing a t-sta-

Table I. AGT Genotypes and Haplotypes in Major Ethnic Groups

\begin{tabular}{|c|c|c|c|c|c|c|c|}
\hline Genotype & Caucasians & Japanese & African-caribbeans & Haplotype & Caucasians & Japanese & African-caribbeans \\
\hline GG-MM & 136 & 3 & 2 & G-M & 0.610 & 0.242 & 0.173 \\
\hline GG-MT & 2 & 1 & 0 & G-T & 0.004 & 0.015 & 0.006 \\
\hline GG-TT & 0 & 0 & 0 & & & & \\
\hline AG-MM & 5 & 0 & 0 & A-M & 0.010 & 0.000 & 0.000 \\
\hline AG-MT & 165 & 41 & 25 & A-T & 0.376 & 0.743 & 0.821 \\
\hline AG-TT & 1 & 2 & 1 & & & & \\
\hline AA-MM & 0 & 0 & 0 & & & & \\
\hline AA-MT & 2 & 0 & 0 & & & & \\
\hline AA-TT & 53 & 52 & 56 & & & & \\
\hline Total & 364 & 99 & 84 & & 1.000 & 1.000 & 1.000 \\
\hline
\end{tabular}

G, A, M, and T denote G(-6), A(-6), M235, and T235, respectively. Haplotype frequencies were estimated by maximum likelihood. Caucasians are a series of normotensive controls (Jeunemaitre, X., I. Inoue, C. Williams, A. Charru, J. Tichet, M. Powers, A.M. Sharma, A.P. Giminez-Roqueplo, A. Hata, P. Corvol, et al., manuscript submitted); Japanese are the controls in Hata et al. (9); African-caribbeans are a random sample of normotensive subjects from Martinique and Guadeloupe. 


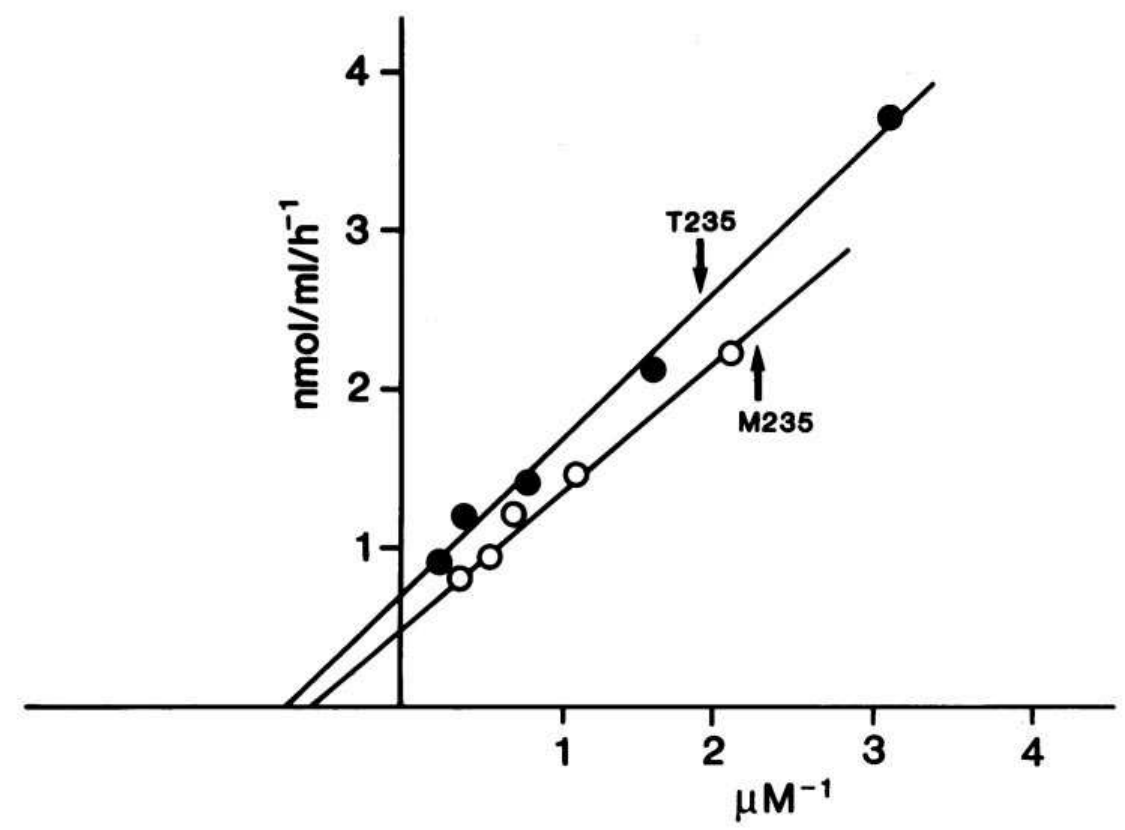

B

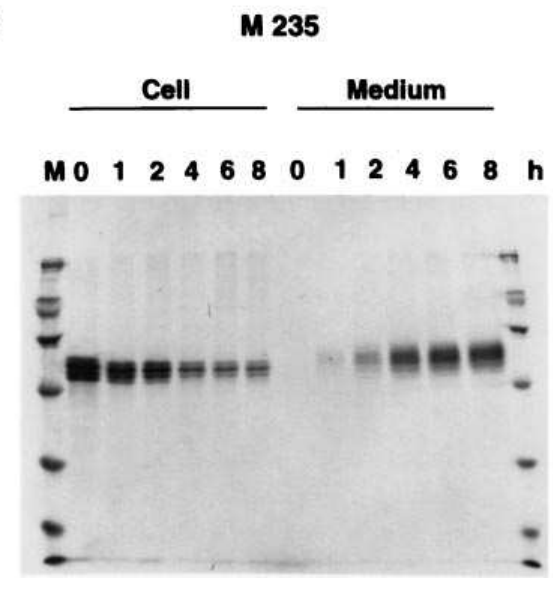

T 235

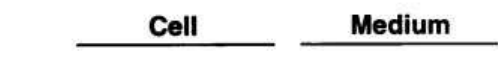

$\begin{array}{llllllllllllll}M & 0 & 1 & 2 & 4 & 6 & 8 & 0 & 1 & 2 & 4 & 6 & 8 & h\end{array}$

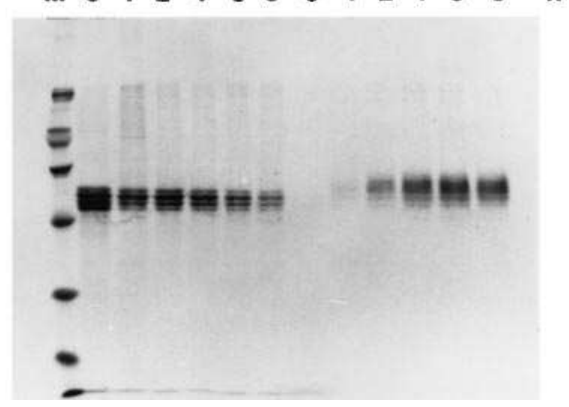

Figure 1. Biochemical analysis of angiotensinogen produced in COS- 1 cells. (A) Double reciprocal plot of the cleavage reaction of angiotensinogen M235 (open circles) and T235 (closed circles) with human renin. (B) Pulse-chase analysis. Pulse chase experiments for angiotensinogen M235 (left) and T235 (right) were performed as described in Methods. M denotes mol. mass markers (from top to bottom: 200, 97, 69, 46, $30 \mathrm{kD})$. tistics after standardization by means and variances within experiment, as described earlier.

\section{Results}

No functional difference can be detected with respect to the substitution at residue 235. Angiotensinogen encoding either M235 or T235 was cloned and expressed transiently in mammalian cells. In several independent experiments, the substitution had no detectable effect on the kinetics of the enzymatic cleavage of the protein by purified recombinant human renin. As can be seen in a typical experiment presented in Fig. $1 A$, M235 and T235 yielded very similar estimates of kinetic parameters, with $\mathrm{K}_{\mathrm{m}}$ equal to 0.88 and $0.82 \mu \mathrm{M}$ and $\mathrm{k}_{\text {cat }}$ equal to 0.98 and $0.89 \mathrm{~s}^{-1}$ respectively. Estimates of kinetic parameters varied among experiments, as they were quite sensitive to calculated substrate concentrations; however, the substitution did not affect either the observed velocities or the catalytic efficiencies of sets of experiments conducted in parallel. Similar conclusions were reached when the kinetics of the reaction was analyzed directly from serial dilution of plasma collected from subjects homozygous for either T235 or M235 (data not shown). Pulse-chase experiments showed no difference between the two proteins in glycosylation, in secretion or in stability (Fig. $1 B$ ); for each protein, half-life was calculated as $\sim 7 \mathrm{~h}$.

A molecular variant in the promoter of AGT is in tight linkage disequilibrium with T235. We documented earlier multiple polymorphisms in the AGT gene (1). Further studies have revealed very strong linkage disequilibrium between T235 and a variant located within its proximal promoter. An adenine, instead of a guanine, six residues upstream from the initiation site for transcription (CCCGGCCAGGGGAAGAAG), is found in $97-99 \%$ of the AGT alleles carrying T235, and in very few of those carrying M235, in all three major ethnic groups examined (Table I). In our previous report, this variant, which we denote $A(-6)$, was identified only when it occurred with another polymorphism, $\mathrm{C}(-20)$, as only the double variant, $A(-6)$ and $C(-20)$, generated a conformational polymorphism detected by electrophoresis under native conditions (see reference 1 , Table IV, row 5). Variant $C(-20)$ occurs in about 


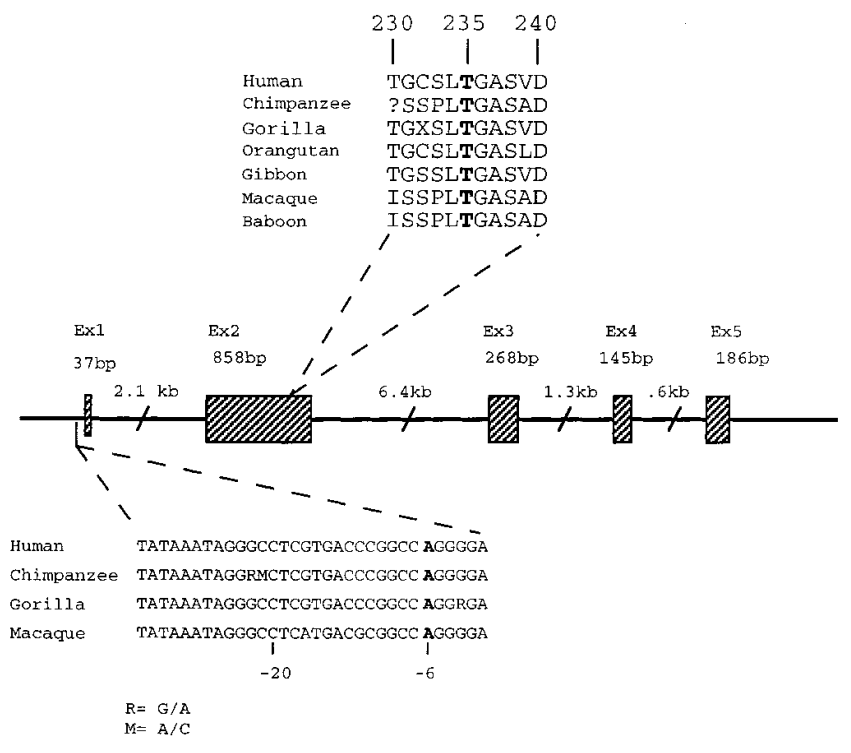

Figure 2. Nucleotide sequence of segments of AGT in primates.

$40 \%$ of the genes carrying T235, and its relative frequency in two large series of hypertensive and normotensive subjects suggests that it does not contribute to disease susceptibility (1; Jeunemaitre, X., I. Inoue, C. Williams, A. Charru, J. Tichet, M. Powers, A.M. Sharma, A.P. Giminez-Roqueplo, A. Hata, P. Corvol, et al., manuscript submitted).

Both markers of hypertension, $A(-6)$ and T235, are present in primates. As an indirect assessment of which of the two alleles at each site first occurred in the course of human evolution, we performed DNA sequencing of the corresponding DNA segments in a series of primates. Alleles $A(-6)$ and T235 were found in all primate species examined (Fig. 2).

Promoter assays reveal a significant effect of the -6 substitution on basal transcription. In tests of the promoter of human AGT, it has been reported that deletions from -1222 to -33 did not change promoter activity significantly. By contrast, removal of the region from -16 to +44 led to sharply reduced expression of a reporter gene in HepG2 cells (23). In independent experiments, a ubiquitous transcription factor binding to a segment of the murine AGT promoter spanning residues -6 to +22 appeared to be a major determinant of basal transcriptional activity (24). These reports pointed to the functional significance in gene expression of the proximal region of the AGT promoter.

We generated fusion genes to express the luciferase gene under the control of segments of human AGT. Three classes of expression vectors were constructed (Fig. 3). Vector I (-256, $+90)$ differs from the shorter vector II $(-70,+90)$ by the inclusion of two putative glucocorticoid responsive elements; vector III $(-256,-17)$ served as a control of AGT promoter expression. Vectors of classes I and II were each constructed in two forms, which differed only by the presence of either a guanine or an adenine at the -6 position. Cultured cells were transfected in parallel to evaluate the effect of this substitution on transcriptional activity. All experiments included parallel transfections of both a positive control expressing luciferase under the control of an SV40 promoter and enhancer, and a promoterless negative control. To correct for variability in

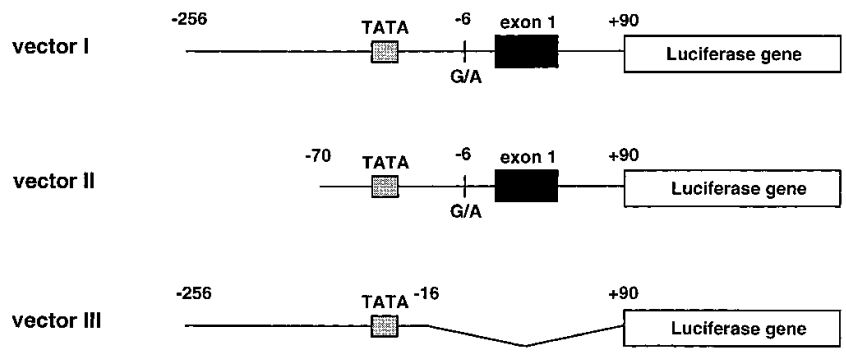

Figure 3. Expression vectors encoding AGT-luciferase fusion genes. AGT promoter segments were inserted upstream from the luciferase gene. In vector III, the AGT segment from -16 to +90 was deleted.

transfection efficiency, every plate was cotransfected with a vector expressing chloramphenicol acetyl transferase (CAT) under the control of an SV40 promoter, and individual luciferase measurements were standardized by their corresponding CAT activities. All experiments were performed in quadruplicate.

Two different cell lines were used, the human hepatoma cell line HepG2, which expresses endogenous AGT, and the human embryonal kidney cell line 293, in which AGT mRNA could not be detected by Northern blot analysis (data not shown). Because of the variability inherent to such experiments, and to achieve high statistical power to detect an effect expected to be moderate (twofold or less), 10 independent experiments were conducted with each cell type.

In HepG2 cells, positive controls yielded standardized activities in large excess (10- to 50-fold) of those exhibited by AGT fusion genes. In 293 cells, the activities recorded for positive controls were similar to those obtained with vector I. Negative controls were, as a rule, an order of magnitude or more below other experimental values. Vector III typically yielded values between one-half and third of those recorded for vector II-G. For clarity of presentation, only the data pertaining to vectors I and II are reported in the figures.

The data obtained in HepG2 cells are presented in Fig. 4 ( $A$ and $B$ ). Considering $A$ for illustrative purposes, it is clear that the largest source of variation occurs among experiments, and that the effect of the nucleotide substitution can be better appreciated by comparing activities within experiments. This conclusion is conveyed more formally by the results of the analysis of variance, where mean squares provide estimates of variance arising from each identified source of variation. While this variance is large among experiments (1718.08), the variance as a result of the substitution effect (753.96) is much in excess of the random variability, or residual variance, among replicates (27.68). Under the hypothesis of no experiment effect and no substitution effect, these three components should provide independent estimates of the same variance. Dividing the mean squares attributed to either effect by the residual mean squares provides a test of significance of the effect, which is distributed as an F-statistic. Thus, the effect of experiment yields a ratio of 1718.08/27.68 $=62.07$, an F-statistic with 9 and 59 degrees of freedom under the null hypothesis. This is highly significant, as the nominal value obtained by reference to the F-distribution is $<10^{-10}$. While also significant, the interaction effect is small compared to other sources of variation tested, suggesting that departures from the assump- 
A

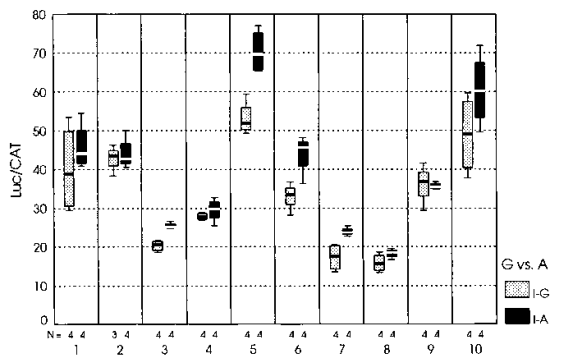

Experment number

\begin{tabular}{lrrrc}
\hline Effect & & Mean & & Difference \\
$G$ & & 33.35 & & $19.3 \%$ \\
A & & 39.78 & & \multicolumn{1}{c}{19.3} \\
\hline Variance & DF & MS & F & P \\
Residual & 59 & 27.68 & & \\
Experiment & 9 & 1718.08 & 62.07 & .00000 \\
G vs A & $\mathbf{1}$ & $\mathbf{7 5 3 . 9 6}$ & $\mathbf{2 7 . 2 4}$ & .00000 \\
Interaction & 9 & 61.12 & 2.21 & .03383 \\
\hline
\end{tabular}

C

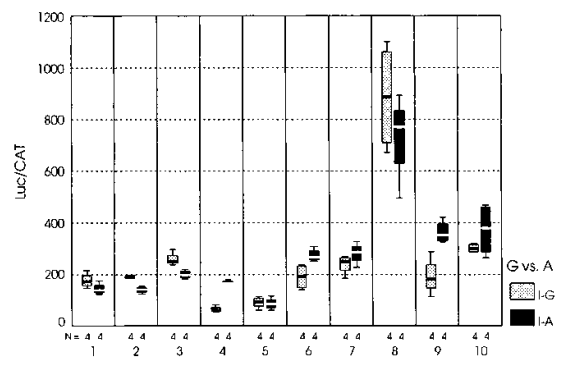

Experiment number

\begin{tabular}{lrrrc}
\hline $\begin{array}{l}\text { Effect } \\
\text { G }\end{array}$ & \multicolumn{1}{c}{ Mean } & & Difference \\
A & 259.28 & & \\
& & 276.10 & & $6.5 \%$ \\
\hline Variance & DF & $\mathbf{M S}$ & $\mathbf{F}$ & $\mathbf{p}$ \\
Residual & 60 & 4949.34 & & \\
Experiment & 9 & 335284.40 & 67.74 & .00000 \\
G vs A & 1 & $\mathbf{5 6 5 9 . 9 3}$ & $\mathbf{1 . 1 4}$ &. $\mathbf{2 8 9 9 3}$ \\
Interaction & $\mathbf{9}$ & 18034.26 & $\mathbf{3 . 6 4}$ & .00112 \\
\hline
\end{tabular}

B

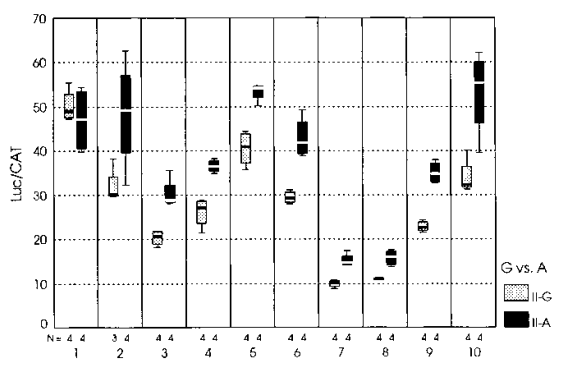

Experiment rumber

\begin{tabular}{lrrrc}
\hline Effect & & $\begin{array}{c}\text { Mean } \\
\text { G }\end{array}$ & & \multicolumn{1}{c}{ Difference } \\
G & & 37.64 & & \multicolumn{1}{c}{$36.7 \%$} \\
\hline Variance & DF & MS & F & P \\
Residual & 59 & 22.66 & & .00000 \\
Experiment & 9 & 1317.09 & 58.11 & .00000 \\
G vs A & 1 & 1977.72 & $\mathbf{8 7 . 2 6}$ & .00167 \\
Interaction & 9 & 78.77 & 3.48 & .00 \\
\hline
\end{tabular}

D

293, vector II

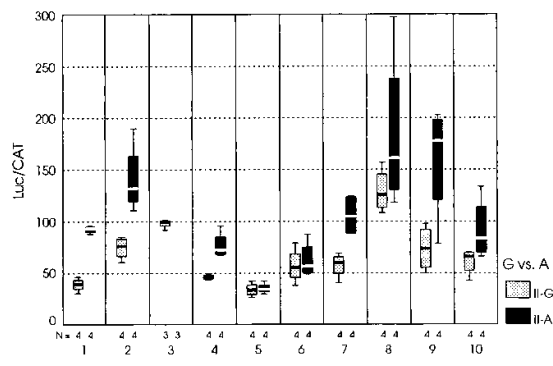

Experiment number

\begin{tabular}{lrrrc}
\hline $\begin{array}{l}\text { Effect } \\
\text { G }\end{array}$ & $\begin{array}{r}\text { Mean } \\
66.17\end{array}$ & & Difference \\
A & & 111.55 & & $68.6 \%$ \\
\hline Variance & DF & MS & \multicolumn{1}{c}{ F } & $\mathbf{p}$ \\
Residual & 60 & 742.12 & & \\
Experiment & 9 & $\mathbf{1 1 7 0 5 . 0 1}$ & 15.77 & .00000 \\
G vs A & $\mathbf{1}$ & $\mathbf{4 1 7 4 6 . 5 6}$ & $\mathbf{5 6 . 2 5}$ & .00000 \\
Interaction & $\mathbf{9}$ & 1688.51 & 2.28 & .02844 \\
\hline
\end{tabular}

Figure 4. Transcriptional activity of AGT-luciferase fusion genes. Two vectors described in Fig. 3 were transfected in human cells from two different lines, HepG2 and 293. Standardized activities are expressed as light unit of luciferase activity divided by $\mu \mathrm{g}$ CAT protein measured by an ELISA. In each panel, the results of three to four parallel transfections with vectors differing only by the presence of either $\mathrm{G}$ or $\mathrm{A}$ at nucleotide -6 , for each of 10 independent experiments, are summarized in terms of the median, estimated 25th and 75th percentiles, and extreme values. Analysis of variance yields estimates of mean effects, and a decomposition of variance according to the sources of variation indicated. $D F$ : degrees of freedom; $M S$ : mean-squares, estimates of variance; $F$ : F-statistic, a variance ratio; $p$ : significance of F-statistic under the null hypothesis. tions of the model have little impact on this statistical inference. The effect of the nucleotide substitution was highly significant $(753.96 / 27.68=27.24$, an F-statistic with 1 and 59 degrees of freedom under the null hypothesis, $P=2.4 \times 10^{-6}$ ), with $\mathrm{A}(-6)$ yielding expression levels $19.3 \%$ higher than $\mathrm{G}(-6)$. Similar results hold for vector II (Fig. 4 B). Variation among experiments was quite significant $\left(\mathrm{F}_{9,59}=58.11, P<\right.$ $\left.10^{-10}\right)$, and the interaction effect was modest $\left(\mathrm{F}_{9,59}=3.48, P=\right.$ 0.002). The substitution effect was quite evident $\left(\mathrm{F}_{9,59}=87.26\right.$, $P<10^{-10}$ ), with expression levels $36.7 \%$ higher for $\mathrm{A}(-6)$ than for $\mathrm{G}(-6)$.

In other analyses, we verified that statistical significance did not result from the presence of extreme, outlying values. We also examined the data after standardization within experiment, as described in Methods, which yielded a statistic distributed as Student's $t$ under the null hypothesis of no substitution effect. In $A$ and $B$ in Fig. 4, there were 39 and 40 observations for vectors with $\mathrm{G}$ or $\mathrm{A}$ at position -6 , respec- tively. In $A$, the means (and SD) of the standardized activities were $-0.52(0.86)$ and $0.51(0.72)$ respectively, yielding $\mathrm{t}=$ 5.76 and $P=8.2 \times 10^{-8}$; similarly in $B$ the corresponding means (and SDs) were $-0.72(0.49)$ and $0.71(0.71)$, yielding $\mathrm{t}=10.45$ and $P=1.1 \times 10^{-16}$. Nonparametric tests were also highly significant. This overall consistency establishes the true statistical significance of the nucleotide substitution effect.

In four additional preliminary experiments conducted in HepG2 cells (data not shown), lower transfection efficiency was achieved but a significant effect of the nucleotide substitution was also noted for both classes of vectors (vector I: $\mathrm{F}_{1,22}=$ $14.49, P=.001,47.4 \%$ higher levels observed with A than with G; vector II: $F_{1,24}=26.78, P=2.7 \times 10^{-5}$, levels $39.6 \%$ higher with A than with $\mathrm{G})$. The multiple additional tests described in Methods yielded uniformly consistent, highly significant results.

The results of experiments conducted in the 293 cell line are summarized in Fig. 4, $C$ and $D$. Vector I led to no significant substitution effect $\left(\mathrm{F}_{9,60}=1.14, P=0.29\right)$. Experiment 
eight in $C$ appeared as a clear outlier, with much higher levels of expression than achieved in other experiments. When this experiment was deleted, however, various statistical tests yielded inconsistent results. The substitution effect appeared significant in the two-way analysis of variance $\left(F_{1,54}=15.15\right.$, $P=0.00027)$, but residual variances among combination of both factors were highly heterogenous; after correction for this effect by standardization, the substitution effect was no longer statistically significant $(\mathrm{t}=1.06, P=0.22)$. For the shorter vector II, by contrast, this effect was very significant $\left(\mathrm{F}_{1,60}=56.25\right.$, $\left.P=3.5 \times 10^{-10}\right)$, with $\mathrm{A}(-6)$ exhibiting levels of expression $68.6 \%$ higher than $\mathrm{G}(-6)$, and this was confirmed by all other analyses.

The expression levels achieved by the AGT-luciferase fusion genes were higher in the 293 cell line than in HepG2 cells, particularly for vector I. This difference was not because of a cell-specific difference in transfection efficiency, however, as the levels observed for the positive controls were actually higher in the HepG2 than in the 293 cell line.

The substitution effect is consistently observed with different plasmid preparations. Although multiple independent plasmid preparations were used in the course of these experi- ments, the extent to which different plasmid isolates can affect the experimental results was specifically examined. For class II vectors with either $\mathrm{G}$ or $\mathrm{A}$ at residue -6 , two different plasmid preparations were used in parallel transfection experiments in the 293 cell line (data not shown). The substitution effect was again significant $\left(\mathrm{F}_{1,8}=45.33, P=0.00015 ; 48 \%\right.$ greater expression levels with $A$ than with $\mathrm{G}$ ), whereas plasmid preparation was not a significant source of variation $\left(\mathrm{F}_{1,8}=0.22, P=\right.$ $0.65)$.

The substitution effect is not an artifact of prokaryotic methylation. The $\mathrm{G}$ to A substitution occurs at a site (CCAGG) recognized by the Escherichia coli $\mathrm{K} 12$ methylase $\mathrm{dcm}$, and methylation of the internal cytosine may affect transcription in various ways (25), including enhancement. This raised the possibility that the differences reported above might be an artifact of prokaryotic methylation. To test this hypothesis, vectors of both classes were propagated in the $\mathrm{dam}^{-} \mathrm{dcm}^{-}$E. coli strain DM1, and the corresponding plasmid isolates were used for another series of transfection experiments. In all instances, the nucleotide substitution produced a highly significant effect on transcription (data not shown), generally higher than observed with plasmids propagated in $\mathrm{DH} 5 \alpha$.
A

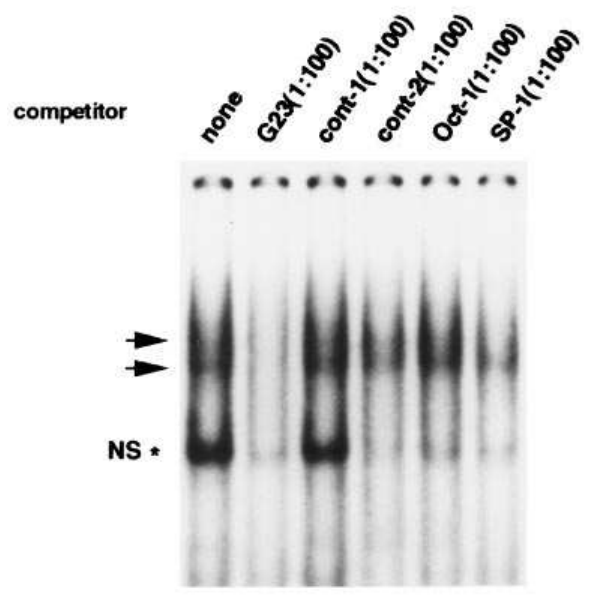

C

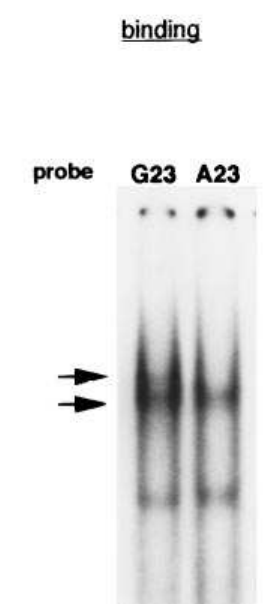

B

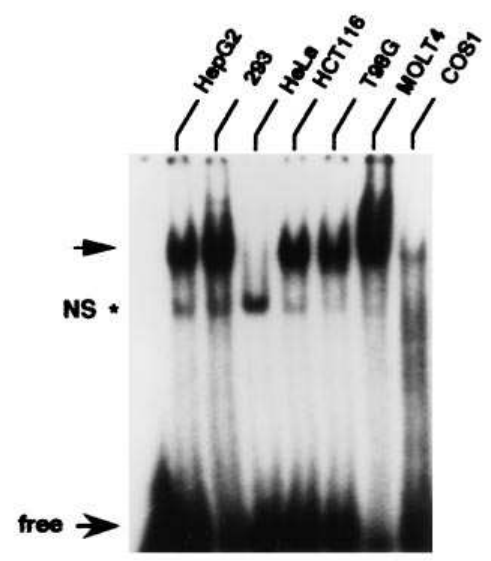

Figure 5. Gel mobility shift assays. (A) Nuclear extract from HepG2 cells was incubated with a double-stranded, radiolabeled oligonucleotide (G23) corresponding to an AGT segment of 23 nucleotides centered of on position -6 with $\mathrm{G}$ at this site, and varying molar excess of unlabeled double stranded competitors. Cont 1 and Cont 2 are two competitors of random composition, while $O c t-1$ and $S p-1$, contain consensus binding sites for the corresponding transcription factors. The arrow points to the specific complex, while $N S$ denotes the nonspecific complex. $(B) \mathrm{Ra}-$ diolabeled G23 oligonucleotide was incubated with nuclear extracts from various cell lines, after preincubation with 100 -fold molar excess of Oct- 1 to reduce formation of the nonspecific complex. Hep G2: human hepatoma; 293: human embryonic kidney; HeLa: human cervical carcinoma; HCT116: human colon carcinoma; $T 98 G$ : human glioblastoma; MOLT4: human T-cell leukemia; $C O S-1$ : monkey kidney. (C and $D$ ) Comparison of the binding affinities of G23 and A23. Extracts were preincubated with Oct-1 in 100-fold molar excess as nonspecific competitor. Incubation with double-stranded, radiolabeled G23 was performed in the presence of varying excess of either G23 or A23 cold competitor. 
An oligonucleotide spanning -6 interacts with at least two distinct protein complexes. That the substitution at nucleotide -6 affects the rate of transcription of AGT implies that nuclear proteins involved in either assembly or regulation of the preinitiation complex interact with the proximal region of the AGT promoter. In gel retardation assays with nuclear extracts prepared from HepG 2 cells, a 23-mer oligonucleotide centered on a $\mathrm{G}$ nucleotide at $-6(\mathrm{G} 23)$ revealed two major retarded complexes (Fig. $5 \mathrm{~A}$ ). The slower moving complex appeared to include two poorly resolved components (arrowheads). Competition experiments with oligonucleotides containing binding sites for a panel of transcription factors, as well as additional oligonucleotides with random composition, showed that the faster complex ( $N S$ in Fig. $5 A$ ) bound to DNA in a nonspecific fashion. By contrast, the slower complex was quantitatively reduced when amounts of homologous competitor were increased (Fig. $5 \mathrm{~A}$ ). It was also slightly reduced by the oligonucleotide harboring an Sp1 consensus binding site; however, experiments involving a radiolabeled oligonucleotide containing an Sp1 binding site revealed a complex of distinct mobility for which G23 exhibited no competition (data not shown). Preincubation of nuclear extracts with increasing amounts of nonspecific competitor (whether poly-(dI-dC) or Oct-1 recognition site) led to a marked reduction in the intensity of the faster complex, although it was not possible to totally compete away this complex and still retain the slower, specific component. Binding by the latter was observed with nuclear extracts from all human cells tested except HeLa (Fig. $5 B$ ).

The nonspecific complex corresponds to human Ku antigen. In an attempt to identify the proteins responsible for the observed DNA binding activities, nuclear extracts prepared from a 2-1 suspension culture of MOLT4 cells were subjected to QAE-sepharose and DNA affinity chromatography. From this preparation, only the nonspecific binding activity could be identified in eluted fractions. Two polypeptides with apparent molecular mass of 70 and $86 \mathrm{kD}$ on denaturing gels were subjected to digestion with endoprotease Lys-C followed by microsequencing. The sequence of two peptide fragments of the
$86 \mathrm{kD}$ protein (IEIFTDLSSRF and KTDTLEDLFP) was identical to the p86 component of the heterodimeric human $\mathrm{Ku}$ nuclear antigen (26); similarly, fragments of the $70 \mathrm{kD}$ component consisted of sequences (LYRETNEPVK, TRTFNT, IMATPEQVGK) found in the p70 component of $\mathrm{Ku}$ antigen (27). It is generally recognized that the $\mathrm{Ku}$ heterodimer binds to DNA ends with no apparent sequence specificity (26). Consequently, all subsequent binding experiments included a 100 -fold molar excess of the Oct-1 oligonucleotide as an additional nonspecific competitor.

Competitive binding studies suggest that the nucleotide substitution affects the binding affinity of the specific complex. Having confirmed the lack of specificity of the faster complex, we examined the binding behavior of the slower complex in search of differences in affinity which could account for the effect of the nucleotide substitution observed in promoter assays. In direct binding experiments involving the G23 and A23 oligonucleotides, A23 appeared to retard only the faster moving component of this complex (Fig. 5 C). Competition studies involving G23 radiolabeled oligonucleotide revealed quantitative reduction of both components of the slow moving complex with increasing concentrations of G23 cold competitor. By contrast, only the faster component was reduced when A23 was used as competitor (Fig. $5 \mathrm{D}$ ). These patterns were reproducible in several independent experiments.

Mutational studies confirm the significance of the -6 region in transcriptional activity. Both the promoter expression and the competitive binding experiments suggested that a transacting factor binds specifically to the proximal promoter of AGT to modulate its expression, and that the affinity of this site is affected by the nucleotide substitution at position -6 . We were not able to characterize this binding site further either by DNase1 footprinting or by methylation interference using total nuclear extracts from HepG2 cells, as these experiments revealed no specific protection or contacts (data not shown).

Systematic mutagenesis was used as an alternative. Oligonucleotides with substitutions scanning the proximal promoter

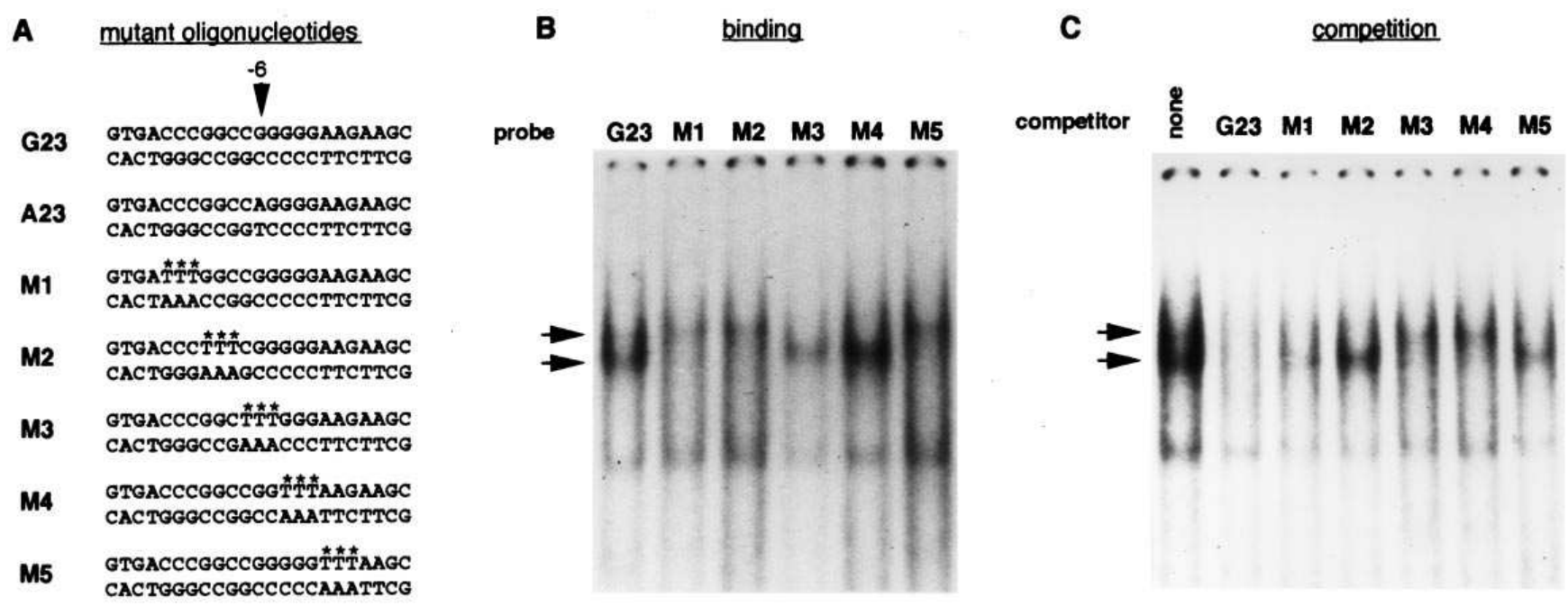

Figure 6. Gel mobility shift assays with mutant oligonucleotides. (A) Natural and mutant oligonucleotides. (B and $C$ ) Gel mobility shift assays with HepG2 nuclear extracts. $(B)$ Binding experiments using radiolabeled probes are as indicated. $(C)$ Competition experiments, using G23 oligonucleotide as radiolabeled probe in all lanes. 
A

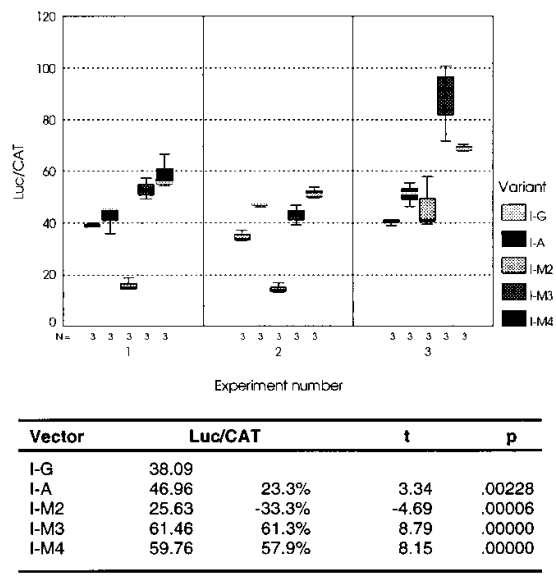

C 293, Mutagenesis with vectorl

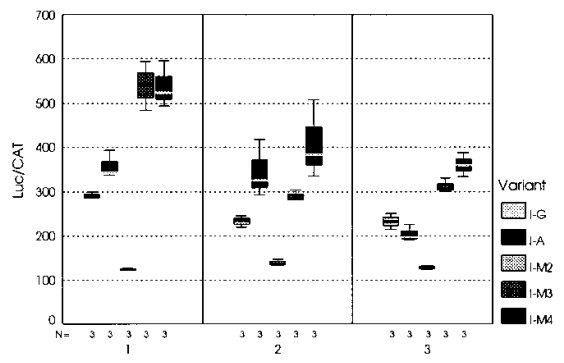

Experment number

\begin{tabular}{llrrr}
\hline Vector & \multicolumn{2}{c}{ Luc/CAT } & \multicolumn{1}{c}{$\mathbf{t}$} & $\mathbf{P}$ \\
\hline I-G & 252.77 & & & \\
I-A & 302.92 & $19.8 \%$ & 2.84 & .00805 \\
I-M2 & 131.03 & $-48.2 \%$ & -6.89 & .00000 \\
I-M3 & 381.00 & $50.7 \%$ & 7.26 & .00000 \\
I-M4 & 435.80 & $72.4 \%$ & 10.36 & .00000 \\
\hline
\end{tabular}

B

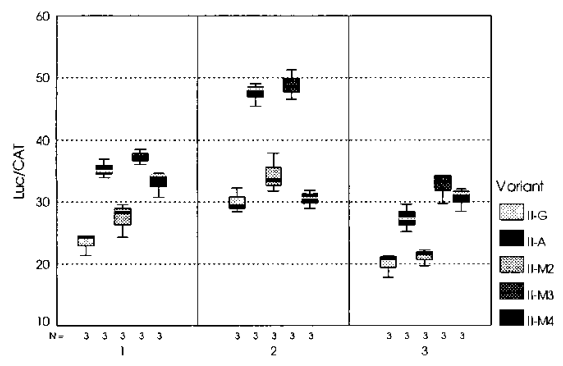

Experiment number

\begin{tabular}{llrrr}
\hline Vector & \multicolumn{2}{c}{ Luc/CAT } & $\mathrm{t}$ & $\mathrm{p}$ \\
\hline II-G & 24.51 & & & \\
II-A & 36.73 & $49.9 \%$ & 12.46 & .00000 \\
II-M2 & 27.64 & $12.7 \%$ & 3.19 & .00328 \\
II-M3 & 39.58 & $61.5 \%$ & 15.36 & .00000 \\
II-M4 & 31.47 & $28.4 \%$ & 7.09 & .00000 \\
\hline
\end{tabular}

293, Mutagenesis with vector II

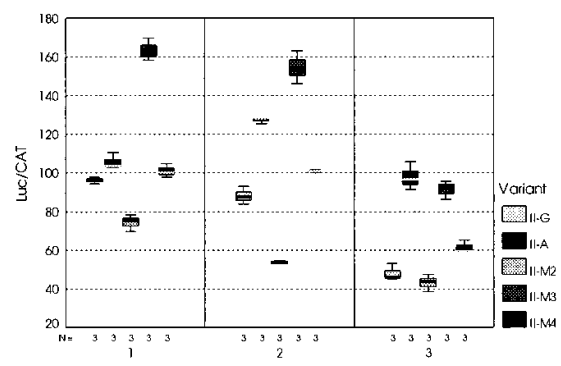

Experiment number

\begin{tabular}{lrrrr}
\hline Vector & \multicolumn{2}{c}{ Luc/CAT } & $\mathbf{t}$ & $\mathbf{p}$ \\
\hline II-G & 77.69 & & & \\
II-A & 110.40 & $42.1 \%$ & 15.23 & .00000 \\
II-M2 & 57.27 & $\mathbf{- 2 6 . 3 \%}$ & -9.51 & .00000 \\
II-M3 & 136.51 & $75.7 \%$ & 27.39 & .00000 \\
II-M4 & 87.83 & $\mathbf{1 3 . 1 \%}$ & 4.72 & .00005 \\
\hline
\end{tabular}

Figure 7. Testing the transcriptional activity of promoter segments of AGT by mutagenesis. Vectors as are defined in Fig. 3, except where the inclusion of the M2, M3, and M4 mutations defined in Fig. $6 A$ is indicated. $t$ : Student's $t$ test contrasting measured transcriptional activities to that recorded for th vector with the vector with $\mathrm{G}$ at site -6 . of AGT from nucleotides -13 to +2 were synthesized (Fig. $6 \mathrm{~A}$ ) and used in gel retardation assays. Direct binding studies suggested differences in affinity of the mutant oligonucleotides for either component of the specific complex (Fig. $6 \mathrm{~B}$ ), and this was further supported by the reciprocal patterns observed when such mutant probes were used as cold competitors (Fig. $6 C$ ). These data provide additional evidence in support of the interpretation that the specific complex consists of at least two unresolved components.

Mutations M2, M3, and M4 were introduced in expression vectors of classes I and II by oligonucleotide-directed mutagenesis and used in promoter assays in both the HepG2 and the 293 cell lines. For each cell type three experiments were performed, each with five experimental vectors, a positive control, and a negative control. All transfections were performed in triplicate. The analysis of the data required the consideration of two factors, experiment and vector, with three and five modalities, respectively. In all instances the overall effects of both factors were highly significant: the F-statistic testing the effect of the vectors, with 4 and 30 degrees of freedom, ranged from 64.09-404.39. This provided confirmation that alterations of the sequence in this region directly affect transcriptional activity in these experiments. The effects of particular substitutions were examined by contrasting the standardized luciferase activities observed for each vector (Fig. 7) to that observed for the reference vector with a guanine at site -6 , yielding statistics distributed as Student's $t$ under the null hypothesis. A consistent picture arose from these four sets of experiments, with similar statistical significance when analyses were performed after standardization within an experiment. Higher expression levels were consistently observed for $\mathrm{A}(-6)$ and mutants M3 and M4 than for $G(-6)$. By contrast, mutant M2 had the opposite effect. These data confirmed the inference arising from our previous experiments, namely that variation in expression and affinity associated with the nucleotide substitution at position -6 appears to result from the specific binding of a trans-acting factor which has the net effect of decreasing transcriptional activity in the vector carrying $G$ rather than $A$ at position -6 . They also suggested the net stimulating effect of another factor binding to the region altered by $\mathrm{M} 2$. 


\section{Discussion}

Two markers of hypertension in very tight association. The very strong association observed between T235 and A(-6) has three important implications: (a) all associations noted between T235 and hypertension extend directly to $\mathrm{A}(-6) ;(b)$ statistical tests cannot resolve the relative significance of either variant in human hypertension; and (c) this new observation expands the range of hypotheses which must be entertained to include the possibility that $\mathrm{A}(-6)$ may be causally related to disease predisposition.

So far, a functional role of the substitution at residue 235 in AGT cannot be either established or ruled out on the basis of the available experimental evidence. By contrast, the data presented here suggest that $A(-6)$ may directly affect angiotensinogen expression. It is striking that both the T235 and the $A(-6)$ variants mark the original form of the gene. This inference derives from two observations: $(a)$ greater genetic diversity in AGT genes carrying T235 compared to their M235 counterparts (Jeunemaitre, X., I. Inoue, C. Williams, A. Charru, J. Tichet, M. Powers, A.M. Sharma, A.P. GiminezRoqueplo, A. Hata, P. Corvol, et al., manuscript submitted), and $(b)$ the presence of T235 and A $(-6)$ in the AGT gene of all species of primates examined. Consequently, M235 and $G(-6)$ are actually the neomorphs, mutations which arose recently in the course of human evolution; the persistence of their association may reflect either chance or correlated response to directional selection.

The transcriptional difference detected may have an impact on physiological function. The statistical significance achieved in the initial series of promoter assays and the replication afforded by subsequent experiments testing the effects of independent plasmid isolates, of plasmid propagation in the DM1 prokaryotic host, or of mutations in this region of the AGT promoter all support the conclusion that the nucleotide substitution affects basal transcription in these assays. The question then is whether a moderate difference in basal transcriptional activity, ranging from 20 to $70 \%$, could be of physiological consequence in vivo and contribute to the development of essential hypertension.

It is clearly not possible to directly extend the results of transfection experiments done with truncated AGT promoters in cultured cells to the function of an intact AGT gene at the level of the whole organism. Manipulation of the number of AGT genes in the mouse by targeted gene duplication has provided direct evidence that a modest increase in gene expression leads to elevated plasma angiotensinogen and a significant rise in blood pressure $(28,29)$. Recent observations provide a direct in vivo correlation for our in vitro observations (Morgan, T., C. Craven, J.M. Lalouel, and K. Ward, manuscript submitted): in total RNA prepared from decidual specimen collected from 39 women who underwent first-trimester elective abortion and were heterozygous at residue 235, T235 was significantly in excess over M235, suggesting a difference in transcriptional activity between the two forms of the AGT gene. Although the correlations noted cannot establish proof of causal relationships, these data support the contention that a modest difference in transcriptional activity, as noted in vitro for variant $A(-6)$, could be of physiological consequence and contribute to the development of essential hypertension.

Preferential binding of a trans-acting factor to $G(-6)$ leads to a net reduction in transcriptional activity. The slower-mov-

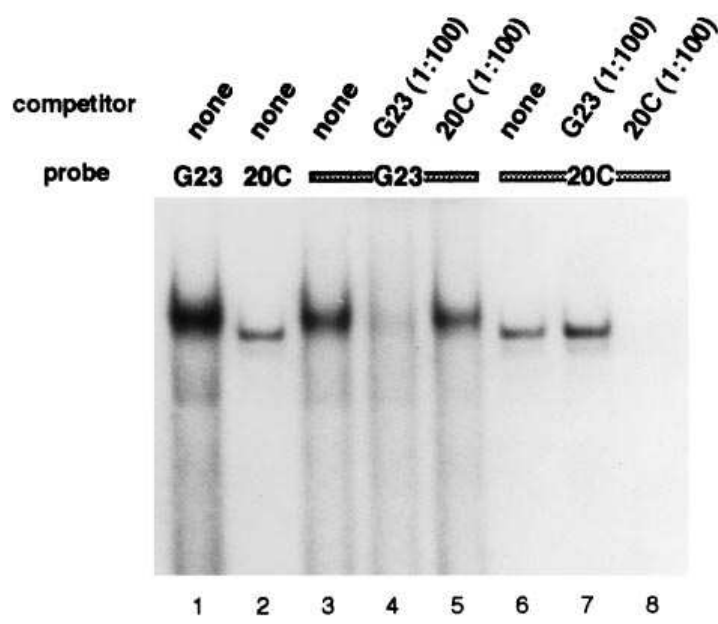

Figure 8. Two proximal segments of the AGT promoter interact with distinct trans-acting factors. Radiolabeled G23 or 20C oligonucleotide, which corresponds to an AGT segment -17 to +6 or -28 to -9 , respectively, was incubated with HepG2 nuclear extract in the presence of either homologous or heterologous cold competitor.

ing complex in gel retardation experiments appeared to be specific, as it could be competed away effectively only by homologous oligonucleotides. Further binding studies suggested that this complex consisted of two distinct components (Fig. 5), with higher affinity of the upper component of the complex for AGT oligonucleotides which have $\mathrm{G}$ rather than $\mathrm{A}$ at position -6 . The lower levels of expression observed with $G$ instead of $\mathrm{A}$ in our transactivation experiments suggested a net reduction in transcriptional activity as a result of an interaction with this upper component. Binding experiments involving G23 and mutant oligonucleotides revealed subtle but reproducible differences in electrophoretic mobility of the slower-moving complex, particularly for mutants M3 and M4, which further documented the heterogeneity of this complex (Fig. 6). Transactivation experiments confirmed the interaction of a factor leading to reduced promoter activity at a site spanning nucleotide -6 and extending in the $3^{\prime}$ direction, the segment probed by mutants M3 and M4 (Fig. 7). They also suggested that an activator may bind to an overlapping site extending in the $5^{\prime}$ direction. While there is published evidence (24) for the interaction of an activator in segment -6 to +22 of the murine AGT promoter when expressed in human HepG2 cells, this site was mapped by mutagenesis downstream from the initiation site of transcription. Evidence for another activator binding to segment -26 to -9 of the proximal promoter of human AGT was reported recently (30); in binding and competition experiments shown in Fig. 8, differences in electrophoretic mobilities and lack of reciprocal cross-competition support the interpretation that the factors interacting at the site centered on nucleotide -6 are distinct from those at this more distal site.

Role of angiotensinogen in sodium balance. The existence of multiple renin-angiotensin systems (RAS) and the multifunctional nature of angiotensin II obscure the expected physiological consequences of sustained, excessive AGT expression.

Transgenic animals with AGT gene duplication document a direct, positive relationship between AGT expression and both plasma angiotensinogen and blood pressure $(28,29)$. 
These experiments demonstrate a causal link between AGT expression and each of these biological parameters; they do not, however, establish causality between an increase in plasma angiotensinogen and elevation in blood pressure. A sustained rise in plasma angiotensinogen could be compensated by a decrease in steady-state plasma renin, leaving the rate of angiotensin II formation unaltered. Predisposition to essential hypertension may be mediated by one or more of the tissue RAS, which may escape this overall feedback regulation $(31,32)$.

What specific mechanism leads to essential hypertension remains a matter of speculation. In light of the significance of sodium balance in blood pressure regulation and in the development of some forms of essential hypertension, the dominant role of the RAS in its regulation, and the role of the kidney in the long-term response to subpressor infusions of angiotensin II (33), it is tempting to agree with Guyton, who long argued in favor of the pathogenic significance of the renal action of angiotensin II. A modest increase in basal expression of AGT could lead to chronic elevation in baseline angiotensin II production either by the circulating RAS or by tissue RAS; an ensuing blood volume expansion would stimulate compensatory mechanisms to maintain volume at the expense of a rise in blood pressure, the kidney acting as the servocontroller of this pressure-volume relationship. Some recent observations in humans are consistent with this hypothesis: the smaller effect on renal blood flow induced by an angiotensin II infusion in AGT T235 homozygotes, compared to other genotypes, may result from a higher endogenous intrarenal concentration of angiotensin II in T235 homozygotes (34).

Evolutionary significance of sodium sensitivity. A wealth of evidence links excess sodium intake to the development of essential hypertension in a substantial proportion of the population of economically advanced societies $(35,36)$. Preliterate societies with habitual low sodium intake experience neither rise of blood pressure with age nor hypertension unless they become exposed to economic development. These observations, when correlated with archeological and anthropological data, support the contention that sodium-sensitivity, rather than sodium-tolerance, emerged originally by natural selection through millions of years of primate and hominid evolution under conditions imposing considerable demands on sodium homeostasis in the sodium-deprived environment of the interior of the African continent (35). The hypothesis has received considerable support from recent experiments demonstrating that increased sodium intake causes a large rise in blood pressure in chimpanzees (37).

Our observation that $\mathrm{A}(-6)$ occurs in all primates examined indicates that it represents the original form of the gene, supports the hypothesis that it predisposes to essential hypertension through sodium-sensitivity, and suggests that sodiumtolerance may have evolved through a relaxation of the selective pressure on sodium homeostasis in relatively recent times in human history.

Neel's thrifty genotype hypothesis. Noting the high frequency at which putative genetic determinants of diabetes mellitus would have to occur in human populations to explain the high prevalence of the disease, James Neel acknowledged that the circumstances under which these factors would have reached such frequency constituted a "first-class genetic mystery" (38). Years earlier, however, he had concluded that if, on the other hand, the high prevalence of the disease was a relatively recent phenomenon, a change in the environment may have been re- sponsible for its increase (13). He proceeded to speculate that a "thrifty" genotype, an asset in early human evolution in response to scarcity of a dietary factor, may have become a liability with the abundance brought about by civilization. In what may prove yet more significant, Neel raised the possibility (39) that "for many disease entities or categories", including specifically hypertension, "ancient physiological balances ultimately under genetic control have been disturbed by shifting environments." It would be a most striking outcome of the experiments reported here if they were ultimately to uphold the remarkable insight of Neel's thrifty genotype hypothesis. Under this evolutionary model, the impact of preeclampsia on fetus and pregnant mother could conceivably have provided the selective mechanism by which the original genotype progressively gave way to the neomorph.

\section{Acknowledgments}

We gratefully acknowledge the advice kindly provided by Barbara Graves concerning this work, and the technical assistance of Ruth Foltz in the preparation of this manuscript. The comments of an anonymous reviewer and discussions with Ryk Ward led to significant improvement of the paper over an initial draft. We also thank Robert Schackmann for peptide synthesis and protein microsequencing, and Jeff Murray and the Yerkes Regional Primate Research Center for DNA samples of primates.

This work was supported in part by a grant from the National Heart, Lung and Blood Institute (HL-45325). A.M. Sharma was supported by the Deutsche Forschungsgemeinschaft (Sh 35/2-1). J.M. Lalouel is an Investigator of the Howard Hughes Medical Institute.

\section{References}

1. Jeunemaitre, X., F. Soubrier, Y.V. Kotelevtsev, R.P. Lifton, C.S. Williams, A. Charru, S.C. Hunt, P.N. Hopkins, R.R. Williams, J.-M. Lalouel, and P. Corvol. 1992. Molecular basis of human hypertension: role of angiotensinogen. Cell. 71:169-180.

2. King, R.A., J.I. Rotter, and A.G. Motulsky. 1992. The Genetic Basis of Common Diseases. Oxford University Press, Oxford, 978 pp.

3. Joint National Committee on Detection, Evaluation and Treatment of Hypertension. 1985. Final report of the subcommittee on definition and prevalence. Hypertension (Dallas). 7:457-468.

4. Ward, R. 1990. Familial aggregation and genetic epidemiology of blood pressure. In Hypertension: Pathophysiology, Diagnosis and Management. J.H. Laragh and B.M. Brenner, editors. Raven Press, New York. 81-100.

5. Lifton, R.P., R.G. Dluhy, M. Powers, G.M. Rich, S. Cook, S. Ulick, and J.-M. Lalouel. 1992. A chimeric 11 $\beta$-hydroxylase/aldosterone synthase gene causes glucocorticoid- remediable aldosteronism and human hypertension. $\mathrm{Na}$ ture (Lond.). 355:262-265.

6. Shimkets, R.A., D.G. Warnock, C.M. Bositis, C. Nelson-Williams, J.H. Hansson, M. Schambelan, J.R. Gill, Jr., S. Ulick, R.V. Milora, J.W. Findling, et al. 1994. Liddle's syndrome: heritable human hypertension caused by mutations in the $\beta$ subunit of the epithelial sodium channel. Cell. 79:407-414.

7. Mune, T., F.M. Rogerson, H. Nikkilä, A.K. Agarwal, and P.C. White. 1995. Human hypertension caused by mutations in the kidney isozyme of 11ß-hydroxysteroid dehydrogenase. Nat. Genet. 10:394-399.

8. Bloem, L.J., A.K. Mantunga, D.A. Tewksbury, and J.H. Pratt. 1995. The serum angiotensinogen concentration and variants of the angiotensinogen gene in white and black children. J. Clin. Invest. 95:948-953.

9. Hata, A., C. Namikawa, M. Sasaki, K. Sato, T. Nakamura, K. Tamura, and J.-M. Lalouel. 1993. Angiotensinogen as a risk factor for essential hypertension in Japan. J. Clin. Invest. 93:1285-1287.

10. Ward, K., A. Hata, X. Jeunemaitre, C. Helin, L. Nelson, C. Namikawa, P.F. Farrington, M. Ogasawara, K. Suzumori, S. Tomoda, et al. 1993. A molecular variant of angiotensinogen associated with preeclampsia. Nat. Genet. 4:59-61.

11. Arngrimsson, R., S. Purandare, M. Connor, J.J. Walker, S. Bjornsson, F. Soubrier, Y. Kotelevtsev, R.T. Geirsson, and H. Bjornsson. 1993. Angiotensinogen: a candidate gene involved in preeclampsia? Nat. Genet. 4:114-115.

12. Loebermann, H., R. Tokuoka, J. Deisenhofer, and R. Huber. 1984. Human $\alpha_{1}$-proteinase inhibitor. Crystal structure analysis of two crystal modifications, molecular model and preliminary analysis of the implications for function. J. Mol. Biol. 177:531-556. 
13. Neel, J.V. 1962. Diabetes mellitus: a "thrifty" genotype rendered detrimental by "progress"? Am. J. Hum. Genet. 14:353-362.

14. Rust, S., H. Funke, and G. Assmann. 1993. Mutagenically separated PCR (MS-PCR): a highly specific one step procedure for easy mutation detection. Nucleic Acids Res. 21:3623-3629.

15. Inoue, I., A. Rohrwasser, C. Helin, X Jeunemaitre, P. Crain, J. Bohlender, R.P. Lifton, P. Corvol, K. Ward, and J.-M. Lalouel. 1995. A mutation of angiotensinogen in a patient with preeclampsia leads to altered kinetics of the renin-angiotensin system. J. Biol. Chem. 270:11430-11436.

16. Harlow, E., and D. Lane. 1988. Antibodies: A Laboratory Manual. Cold Spring Harbor Laboratory Press, Cold Spring Harbor, NY, 726 pp.

17. Shepherd, N.S., B.D. Pfrogner, J.N. Coulby, S.L. Ackerman, G. Vaidyanathan, R.H. Sauer, T.C. Balkenhol, and N. Sternberg. 1994. Preparation and screening of an arrayed human genomic library generated with the P1 cloning system. Proc. Natl. Acad. Sci. USA. 91:2629-2633.

18. Ho, H.D., S.D Hunt, R.M. Horton, J.K. Pullen, and L.R. Pease. 1989. Site-directed mutagenesis by overlap extension using the polymerase chain reaction. Gene (Amst.). 77:51-59.

19. Dignam, J.D., R.M. Lebovitz, and R.G. Roeder. 1983. Accurate transcription initiation by RNA polymerase II in a soluble extract from isolated mammalian nuclei. Nucleic Acids Res. 11:1475-1489.

20. Garabedian, M.J., J. LaBaer, W.-H. Liu, and J.R. Thomas. 1993. Analysis of protein-DNA interactions. In Gene Transcription. B.D. Hames and S.J. Higgins, editors. Oxford University Press, Oxford. 243-293.

21. Schreiber, E., P. Matthias, M.M. Muller, and W. Schaffner. 1989. Rapid detection of octamer binding proteins with 'mini-extracts', prepared from a smaller number of cells. Nucleic Acids Res. 17:6419.

22. Fernandez, J., M. DeMott, D. Atherton, and S.M. Mische. 1992. Internal protein sequence analysis: enzymatic digestion for less than $10 \mu \mathrm{g}$ of protein bound to polyvinylidene difluoride or nitrocellulose membranes. Anal. Biochem. 201:255-264.

23. Fukamizu, A., S. Takahashi, M.S. Seo, M. Tada, K. Tanimoto, S. Uehara, K. Murakami. 1989. Structure and expression of the human angiotensinogen gene. Identification of a unique and highly active promoter. J. Biol. Chem. 265:7576-7582

24. Tamura, K., S. Umemura, M. Ishii, K. Tanimoto, K. Murakami, and A. Fukamizu. 1994. Molecular mechanism of transcriptional activation of angiotensinogen gene by proximal promoter. J. Clin. Invest. 93:1370-1379.

25. Volpe, P., P. Iacovacci, R.H. Butler, and T. Eremenko. 1993. 5-methylcytosine in genes with methylation-dependent regulation. FEBS (Fed. Eur. Biochem. Soc.) Lett. 329:233-237.

26. Mimori, T., and J.A. Hardin. 1986. Mechanism of interaction between Ku protein and DNA. J. Biol. Chem. 261:10375-10379.

27. Reeves, W.H., and Z.M. Sthoeger. 1989. Molecular cloning of cDNA encoding the p70 (Ku) lupus autoantigen. J. Biol. Chem. 264:5047-5052.

28. Smithies, O., and H.-S. Kim. 1994. Targeted gene duplication and disruption for analyzing quantitative genetic traits in mice. Proc. Natl. Acad. Sci. USA. 91:3612-3615.

29. Kim, H.-S., J.H. Krege, K.D. Kluckman, J.R. Hagaman, J.B. Hodgin, C.F. Bets, J.C. Jennette, T.M. Coffman, N. Maeda, and O. Smithies. 1995. Genetic control of blood pressure and the angiotensinogen locus. Proc. Natl. Acad. Sci. USA. 92:2635-2739.

30. Yanai, K., Y. Nibu, K. Murakami, and A. Fukamizu. 1996. A cis-acting DNA element located between TATA box and transcription initiation site is critical in response to regulatory sequences in human angiotensinogen gene. $J$. Biol. Chem. 27:15981-15986.

31. Campbell, D.J., and J.F. Habener. 1986. Angiotensinogen gene is expressed and differentially regulated in multiple tissues of the rat. J. Clin. Invest. 78:31-39.

32. Campbell, D.J. 1987. Tissue renin-angiotensin system: sites of angiotensin formation. J. Cardiovasc. Pharmacol. 10(Suppl. 7):S1-S8.

33. Guyton, A.C., T.E. Lohmeier, A.W. Cowley, Jr., J.E. Hall, T.G. Coleman, and D.B. Young. 1980. The renin-angiotensin system: its effect on renal retention of sodium and on long-term servocontrol of arterial pressure. In Arterial Pressure and Hypertension. A.C. Guyton, editor. W.B. Saunders Co., Philadelphia. 180-204.

34. Hopkins, P.N., R.P. Lifton, N.K. Hollenberg, X. Jeunemaitre, M. Hallouin, J. Skuppin, C.S. Williams, R.G. Dluhy, J.-M. Lalouel, R.R. Williams, and G.H. Williams. 1996. Blunted renal vascular response to angiotensin II is associated with a common variant of the angiotensinogen gene and obesity. J. Hypertension. 14:199-207.

35. Denton, D. 1984. The Hunger for Salt. An Anthropological, Physiological and Medical Analysis. Springer-Verlag, Berlin. 650 pp.

36. Dyer, A.R., R. Stamler, P. Elliott, and J. Stamler. 1995. Dietary salt and blood pressure. Nat. Med. 1:994-996.

37. Denton, D., R. Weisinger, N.I. Mundy, E.J. Wickings, A. Dixson, P Moisson, A.M. Pingard, R. Shade, D. Carey, R. Ardaillou, et al. 1995. The effect of increased salt intake on blood pressure of chimpanzees. Nat. Med. 1:1009-1016.

38. Neel, J.V. 1970. The genetics of diabetes mellitus. In Early Diabetes. R. Camerini-Dávalos and H.S. Cole, editors. Academic Press, Inc., Orlando, FL. $3-10$.

39. Neel, J.V. 1967. Current concepts of the genetic basis of diabetes mellitus and the biological significance of the diabetic predisposition. In Supplement to the Proceedings of the Sixth Congress of the International Diabetes Federation, Stockholm, Excerpta Medica International Congress Series No. 172S. Excerpta Medica, Amsterdam. 68-78. 